\title{
Thermal Study of Anhydrides Cured Tetrafunctional Cardo Epoxy Resin
}

\author{
Jignesh P. Patel and Parsotam H. Parsania \\ Polymer Chemistry Division, Department of Chemistry UGC-SAP and DST-FIST, \\ Saurashtra University, Rajkot, Gujarat 360 005, India \\ Correspondence should be addressed to Parsotam H. Parsania; phparsania22@gmail.com
}

Received 17 June 2013; Accepted 6 August 2013

Academic Editors: D. Das and S. Thomas

Copyright (C) 2013 J. P. Patel and P. H. Parsania. This is an open access article distributed under the Creative Commons Attribution License, which permits unrestricted use, distribution, and reproduction in any medium, provided the original work is properly cited.

\begin{abstract}
Tetrafunctional cardo epoxy resin (EBCF) was cured by using $10 \mathrm{wt} \%$ maleic anhydride (MA), pyromellitic dianhydride (PMDA), phthalic anhydride (PA), tetrahydrophthalic anhydride (THPA), tetrabromophthalic anhydride (TBPA), and tetrachlorophthalic anhydride (TCPA) as hardeners at $120^{\circ} \mathrm{C}$ for $40-105 \mathrm{~min}$ (gel time) and then postcured $1 \mathrm{~h}$ at $130^{\circ} \mathrm{C}$. Gel time is found to depend on the structure of the anhydrides used. Cured samples were found insoluble in common solvents. Cured and uncured EBCF were characterized by FTIR, DSC, and TGA techniques. Cured and uncured resins followed multistep degradation reactions. Kinetic parameters, namely, order of degradation, energy of activation, frequency factor, and entropy change, were determined according to the Anderson-Freeman method and interpreted in light of the nature of hardeners used for curing purpose. The resins followed integral or fractional order degradation kinetics. Complex degradation reactions are due to different types of linkages in cured resins. Both nature and structure of resin and hardeners affected the curing behavior and the resultant thermal properties of the cured resins.
\end{abstract}

\section{Introduction}

Epoxy resins are well known for their outstanding processing behavior and physicochemical properties such as mechanical stiffness and toughness; chemical, moisture, and corrosion resistance. They are most widely used in advanced technologies, aerospace, electronics, communication, adhesives, primers, coatings, and semiconductor encapsulation industries. They are also used for storage and management of nuclear waste as matrices for advanced fiber-reinforced composites [1-6]. The basic properties of epoxy resins can be modified by blending different resins, by selection of curing agents, and by the use of modifiers and fillers.

Multifunctional epoxy resins are well known for their high glass transition temperatures, high decomposition temperatures, long term high temperature performance, and good wet strength performance [7-11]. These materials suffer two important limitations because of their intrinsic brittle nature and considerable moisture absorption tendency from environment, which adversely affect most physicomechanical properties of the fabricated articles. Both these drawbacks increase by enhancing the crosslink density of the network.

To the best of our knowledge, no work has been reported on anhydrides cured multifunctional epoxy resin containing cyclohexyl as a cardo (Latin meaning a loop) group, which encouraged us to investigate the present work. In this paper, we have reported curing study of cardo group containing tetrafunctional epoxy resin (Scheme 1) by using $10 \mathrm{wt} \%$ of various anhydrides. The cured resins are characterized by IR, DSC, and TGA techniques. Our future objective is to prepare and characterize fiber reinforced composites of this resin and hardeners used.

\section{Experimental}

2.1. Materials. Solvents and chemicals used were of laboratory grade and purified prior to their use [12]. Tetrafunctional cardo epoxy resin (EE 800) was synthesized according to our recent work [13]. Maleic anhydride (MA) 


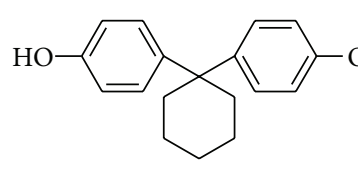

$0.5 \mathrm{~mol}$

$\mathrm{HCHO}$

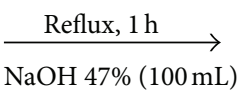

$56 \mathrm{~mL}$
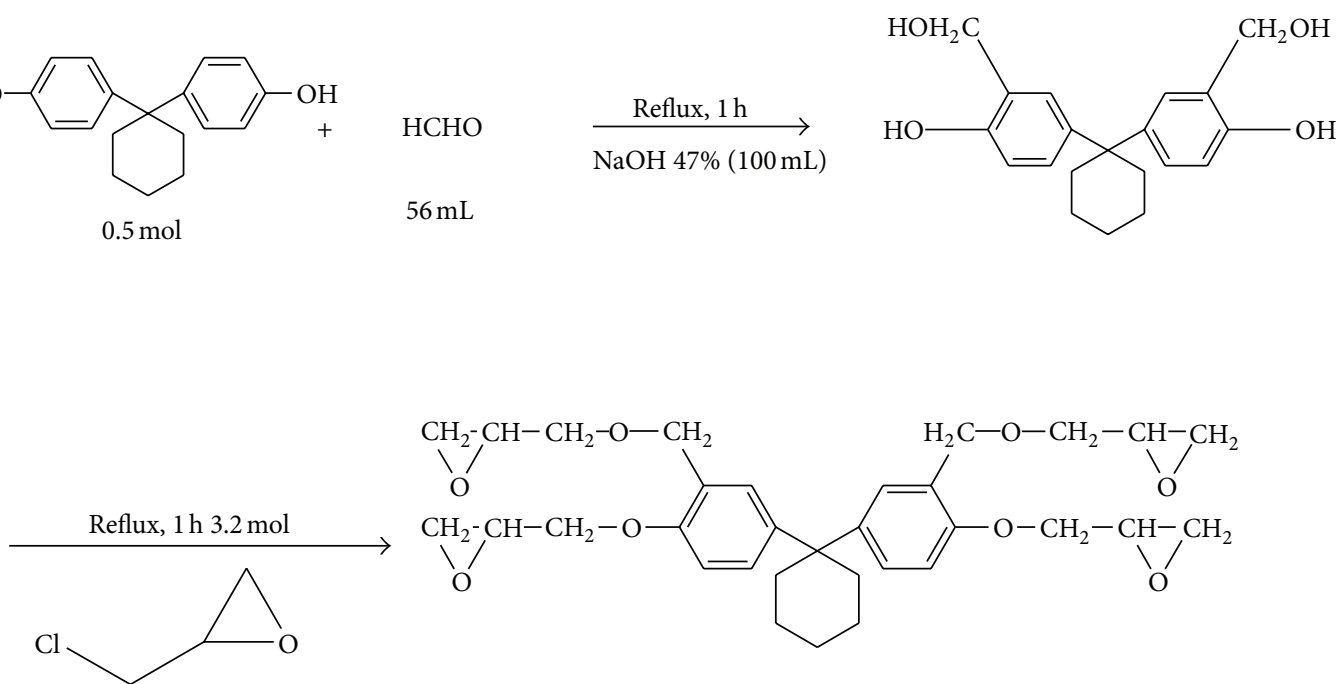

SCHEME 1

TABLE 1: Gel time of EBCF cured by various anhydrides at $120^{\circ} \mathrm{C}$.

\begin{tabular}{lc}
\hline Sample & Gel time $(\mathrm{min})$ \\
\hline EBCF-PA & 105 \\
EBCF-MA & 80 \\
EBCF-THPA & 70 \\
EBCF-TBPA & 40 \\
EBCF-TCPA & 75 \\
EBCF-PMDA & 45 \\
\hline
\end{tabular}

(Sisco-Chem, Mumbai), phthalic anhydride (PA) (SiscoChem, Mumbai), tetrahydrophthalic anhydride (THPA) (Merck, Germany), tetrachlorophthalic anhydride (TCPA) (National Chemicals Vadodara), tetrabromophthalic anhydride (TBPA) (Lancaster, England), and pyromellitic dianhydride (PMDA) (Spectrochem, Mumbai) were used as hardeners and received.

2.2. Curing Study. In the present investigation, curing study of EBCF was carried out by using $10 \mathrm{wt} \%$ of PA, MA, THPA, TBPA, TCPA, and PMDA as hardeners at $120^{\circ} \mathrm{C}$. Into six different test tubes, $2 \mathrm{~g} \mathrm{EBCF}$ and $0.2 \mathrm{~g}$ hardener were dissolved in $5 \mathrm{~mL}$ acetone and were placed in a water bath at about $70^{\circ} \mathrm{C}$. Acetone was allowed to evaporate slowly with stirring. Then the test tubes were placed in an oil bath at $120^{\circ} \mathrm{C}$. With the progress of the curing reaction, viscosity of the resin was found to increase, and stirring was also found difficult. The time at which viscous resin was set into infusible mass was considered as gel time. The gel times of different hardeners cured EBCF are reported in Table 1. The samples were further postcured at $130^{\circ} \mathrm{C}$ for $1 \mathrm{~h}$. Cured samples are insoluble in common solvents. Hereafter, the cured samples are designated as EBCF-MA, EBCF-PA, EBCF-THPA, EBCFTCPA, EBCF-TBPA, and EBCF-PMDA.
2.3. Measurements. Fourier transform infrared FTIR spectra (KBr pellets) of EBCF and anhydrides cured EBCF samples were scanned on a Shimadzu FTIR-8400 spectrometer over the frequency range from 4000 to $400 \mathrm{~cm}^{-1}$. Differential scanning calorimetric (DSC) and thermogravimetric analyses (TGA) were carried out on a Shimadzu DSC60 and PyrisI Perkin Elmer TGA at $10^{\circ} \mathrm{C} \mathrm{min}^{-1}$ heating rate in nitrogen atmosphere.

\section{Results and Discussion}

3.1. IR Spectral Analysis. IR spectra of EBCF and anhydrides cured EBCF are presented in Figures 1 and 2. EBCF showed characteristic IR absorption peaks $\left(\mathrm{cm}^{-1}\right)$ at 3339 (OH str.), 1244 (Aryl-O-Alkyl str.), 1119 (Alkyl-O-Alkyl str.), and 876 and 816 (C-O str. of epoxide). Cured EBCF showed absorption peaks at 3651-3524 (broad O-H str.), 1740-1722 (ester str.), 1265-1217 (Aryl-O-alkyl str.) and 11671071 (Alkyl-O-alkyl str.), 1121-1109 (C-OH str.), and 13541310 (O-H def.), beside the normal modes of aromatic and aliphatic groups. Upon curing, peaks due to epoxide $\mathrm{C}-\mathrm{O}$ str. disappeared, and new $\mathrm{C}=\mathrm{O}$ str. peak appeared. Aryl-Oalkyl str. and alkyl-O-alkyl str. peaks also shifted from 1244 to $1265-1217$ and from 1119 to $1167-1071 \mathrm{~cm}^{-1}$, which are due to the different structure and nature of the hardeners used. In case of cured resins, absorption peaks over the range 1500 $650 \mathrm{~cm}^{-1}$ are masked by ester and hydroxyl groups. Thus, IR spectral data confirmed transformation of epoxy groups into network structure. Both nature and structure of the resin and hardeners affected curing behavior of the resin.

3.2. Thermal Analysis. DSC curves of cured and uncured EBCF are presented in Figures 3 and 4. Endothermic/exothermic transitions are reported in Table 2. A broad 
TABLE 2: DSC and TGA data of anhydrides cured and uncured EBCF.

\begin{tabular}{|c|c|c|c|c|c|c|}
\hline Sample & DSC transition $\left({ }^{\circ} \mathrm{C}\right)$ & $T_{0}\left({ }^{\circ} \mathrm{C}\right)$ & Decomposition range $\left({ }^{\circ} \mathrm{C}\right)$ & $T_{\max }\left({ }^{\circ} \mathrm{C}\right)$ & $\%$ wt loss & Residue at $700^{\circ} \mathrm{C}$ \\
\hline \multirow{4}{*}{$\mathrm{EBCF}$} & 68.3 (Endo) & \multirow{4}{*}{120} & $120-210$ & 187.9 & 10.2 & \multirow{4}{*}{-} \\
\hline & 188 (Endo) & & $340-400$ & 369.9 & 11.3 & \\
\hline & 259.8 (Endo) & & $455-515$ & 505.1 & 28.9 & \\
\hline & 354.5 (Еxo) & & $515-550$ & 548.2 & 20.6 & \\
\hline \multirow{2}{*}{ EBCF-MA } & \multirow{2}{*}{244.9 (Endo) } & \multirow{2}{*}{230} & $230-370$ & 338.6 & 16.8 & \multirow{2}{*}{$36.9(600)$} \\
\hline & & & $415-510$ & 433.6 & 30.5 & \\
\hline \multirow{4}{*}{ EBCF-PMDA } & \multirow{4}{*}{258.0 (Endo) } & \multirow{4}{*}{170} & $170-250$ & - & 11.7 & \multirow{4}{*}{33.5} \\
\hline & & & $250-280$ & 267.5 & 4.3 & \\
\hline & & & $280-390$ & 329.3 & 20.6 & \\
\hline & & & $390-500$ & 456.8 & 25 & \\
\hline \multirow{3}{*}{ EBCF-PA } & \multirow{3}{*}{$\begin{array}{l}168.5 \text { (Endo) } \\
266.6 \text { (Endo) }\end{array}$} & \multirow{3}{*}{135} & $135-270$ & - & 12.7 & \multirow{3}{*}{26.4} \\
\hline & & & $270-380$ & 322.1 & 20.6 & \\
\hline & & & $390-500$ & 446.3 & 31 & \\
\hline \multirow{2}{*}{ EBCF-THPA } & 133.9 (Endo) & \multirow{2}{*}{255} & $255-360$ & 340 & 16.1 & \multirow{2}{*}{20.7} \\
\hline & 289.8 (Endo) & & $360-520$ & 421.3 & 57.2 & \\
\hline \multirow{3}{*}{ EBCF-TBPA } & \multirow{3}{*}{$\begin{array}{l}232.5 \text { (Endo) } \\
313.4 \text { (Exo) }\end{array}$} & \multirow{3}{*}{170} & $170-255$ & 256 & 8.1 & \multirow{3}{*}{29.5} \\
\hline & & & $260-315$ & 285.5 & 14.3 & \\
\hline & & & $375-485$ & 407.1 & 20.9 & \\
\hline \multirow{2}{*}{ EBCF-TCPA } & 212.8 (Endo) & \multirow{2}{*}{150} & $150-270$ & 219.5 & 12.9 & \multirow{2}{*}{52.6} \\
\hline & 253.2 (Exo) & & $270-350$ & 288.6 & 11.5 & \\
\hline
\end{tabular}

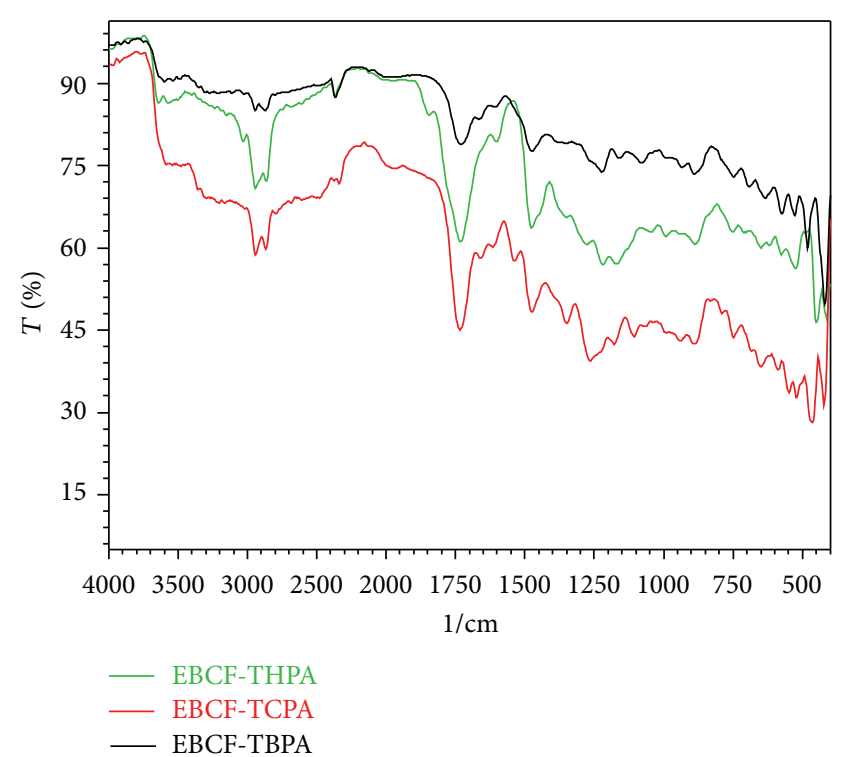

FIgURE 1: IR spectra of EBCF-THPA, EBCF-TCPA, and EBCFTBPA.

endothermic transition at $68.3^{\circ} \mathrm{C}$ is assigned as melting transition of EBCF. Two broad endothermic transitions $\left(188^{\circ} \mathrm{C}\right.$ and $\left.259.8^{\circ} \mathrm{C}\right)$ and one broad exothermic transition $\left(354.5^{\circ} \mathrm{C}\right)$ are due to some chemical change (probably condensation of unreacted methylol groups with elimination of formaldehyde and water), which are further confirmed by weight losses over those temperatures in its TGA curve (Figure 5). Endothermic

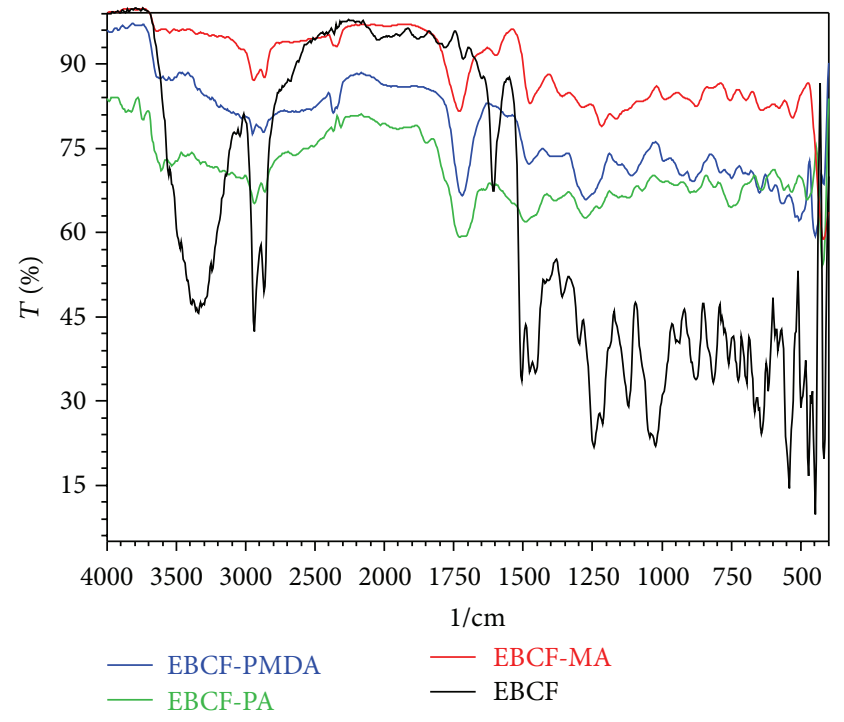

FIgure 2: IR spectra of EBCF, EBCF-MA, EBCF-PA, and EBCFPMDA.

transitions in cured resins at $244.9^{\circ} \mathrm{C}$ (EBCF-MA); $258^{\circ} \mathrm{C}$ (EBCF-PMDA); $168.5^{\circ} \mathrm{C}$ and $266.6^{\circ} \mathrm{C}$ (EBCF-PA); $232.5^{\circ} \mathrm{C}$ and $313.4^{\circ} \mathrm{C}$ (EBCF-TBPA); and $212.8^{\circ} \mathrm{C}$ and $253.2^{\circ} \mathrm{C}$ (EBCFTCPA) is/are assigned as decomposition reaction and further confirmed by weight loss in corresponding TG curve (Figures 5 and 6). Endothermic transitions of EBCF-THPA at $133.9^{\circ} \mathrm{C}$ and $289.8^{\circ} \mathrm{C}$ are assigned as physical and chemical change, respectively, and further confirmed by no weight loss and 


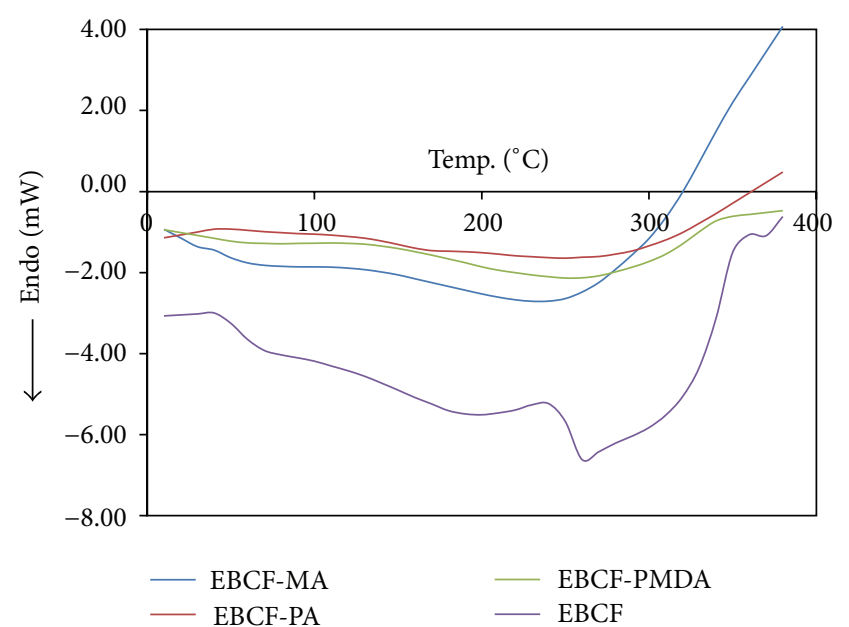

FIgURE 3: DSC thermograms of EBCF, EBCF-MA, EBCF-PA, and EBCF-PMDA at $10^{\circ} \mathrm{C} \mathrm{min}^{-1}$ heating rate in nitrogen atmosphere.

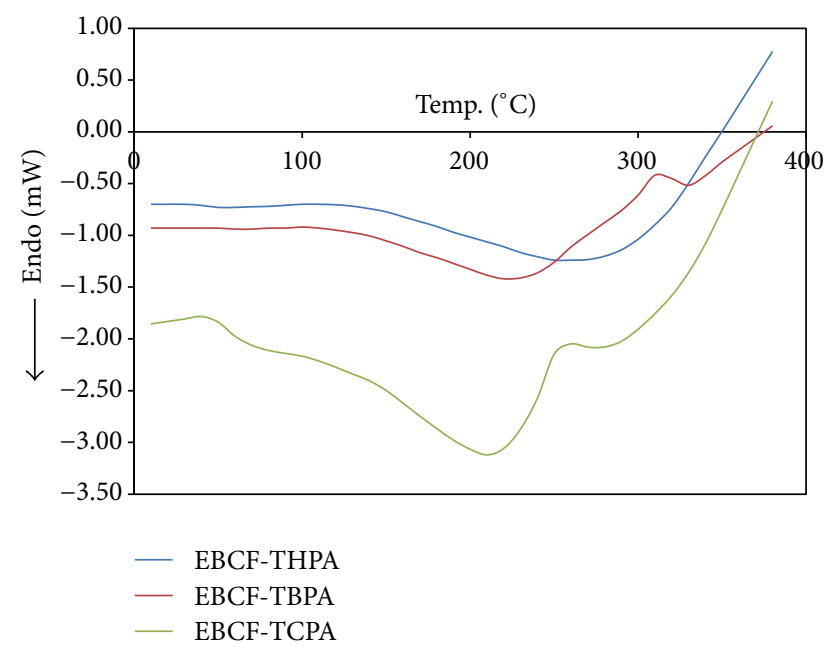

Figure 4: DSC thermograms of EBCF-THPA, EBCF-TCPA, and EBCF-TBPA at $10^{\circ} \mathrm{C} \mathrm{min}{ }^{-1}$ heating rate in nitrogen atmosphere.

weight loss over those temperatures in its TG curve (Figure 6).

TG curves of cured and uncured EBCF are presented in Figures 5 and 6 , from which it is clear that decomposition reactions are very complex and followed multistep degradation reactions. Initial decomposition temperature $\left(T_{0}\right)$, decomposition range, temperature of maximum weight loss $\left(T_{\max }\right), \%$ weight loss involved in each step, and \% residue remained at $700^{\circ} \mathrm{C}$ are reported in Table 2. Decomposition of epoxy resin begins with dehydration of secondary hydroxyl groups followed by homolytic cleavage of the formed allylic bond $[14,15]$. Repetition of bond cleavage of the epoxy network leads to the evaporation of the low molecular weight fragments, whereas polymerization of unsaturated

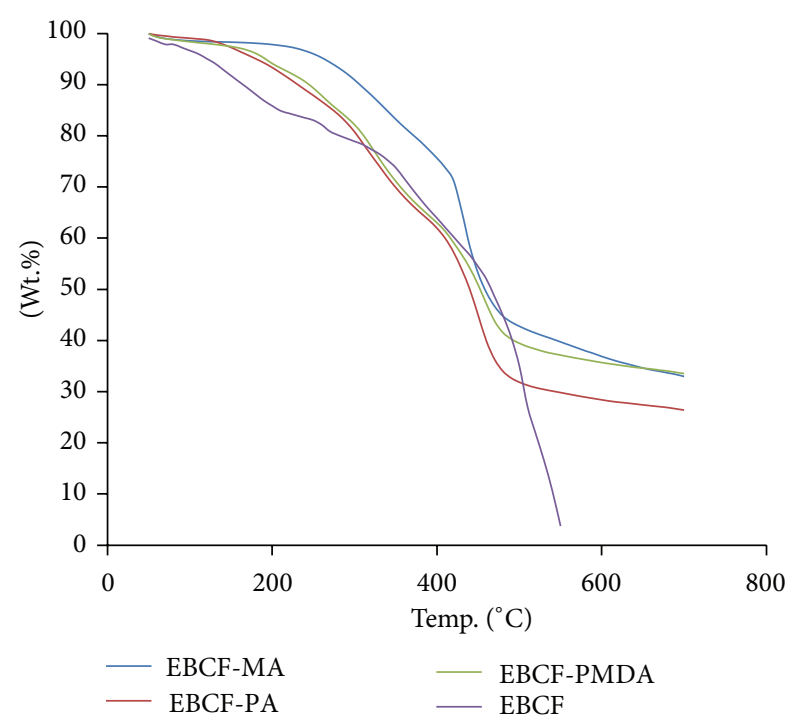

FIGURE 5: TGA thermograms of EBCF, EBCF-MA, EBCF-PA, and

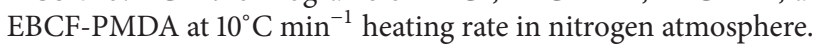

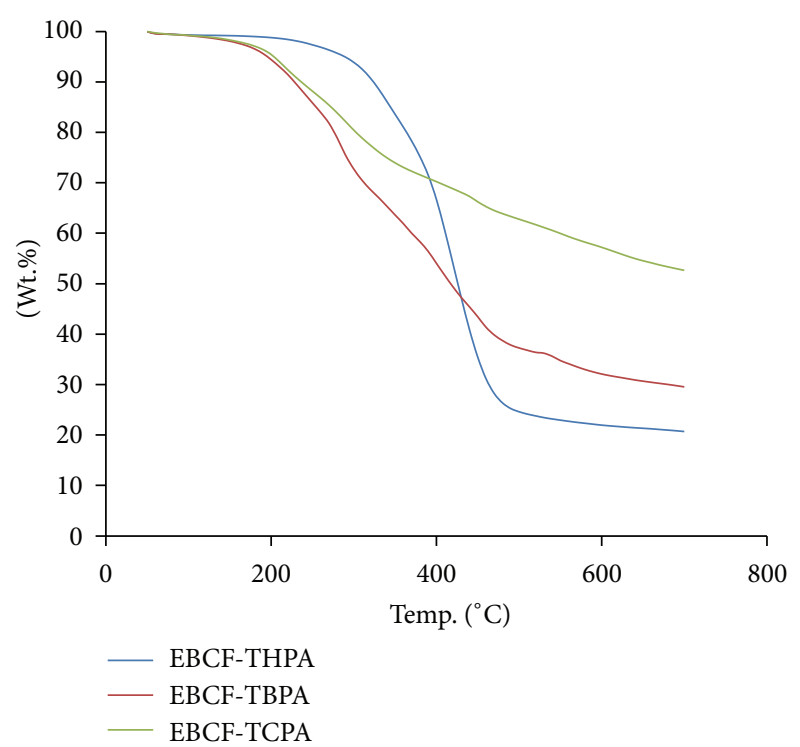

FIgURE 6: TGA thermograms of EBCF-THPA, EBCF-TCPA, and

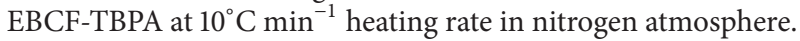

fragments results from dehydration and subsequent aromatization contributing into charring. Crosslinking density depends on the chemical structure of the resin, curing agent, and their functionalities, also on the curing mechanism and conditions selected. Thermal stability order is EBCF-THPA $>$ EBCF-MA $>$ EBCF-PMDA = EBCF-TBPA $>$ EBCF-PA $>$ EBCF. The use of MA and THPA as hardeners for EBCF resulted in improvements in good thermal stability, while other hardeners improved it to some extent.

Associated kinetic parameters such as energy of activation $\left(E_{a}\right)$, frequency factor $(A)$, order of reaction $(n)$, 
TABLE 3: Kinetic parameters of anhydrides cured and uncured EBCF.

\begin{tabular}{|c|c|c|c|c|c|}
\hline Sample & $\begin{array}{c}E_{a} \\
\left(\mathrm{~kJ} \mathrm{~mol}^{-1}\right)\end{array}$ & $n$ & $\begin{array}{c}A \\
\left(\mathrm{~s}^{-1}\right)\end{array}$ & $\begin{array}{c}\Delta S^{*} \\
\left(\mathrm{JK}^{-1} \mathrm{~mol}^{-1}\right)\end{array}$ & $R^{2}$ \\
\hline \multirow{4}{*}{$\mathrm{EBCF}$} & 43.90 & 0.69 & $4.80 \times 10^{2}$ & -197.1 & 0.986 \\
\hline & 29.93 & 0.26 & 0.39 & -259.1 & 0.973 \\
\hline & 309.61 & 0.78 & $6.21 \times 10^{18}$ & 106.9 & 0.983 \\
\hline & 155.97 & 0.19 & $3.85 \times 10^{7}$ & -108.1 & 0.992 \\
\hline \multirow{2}{*}{ EBCF-MA } & 28.27 & 0.27 & 0.39 & -258.6 & 0.961 \\
\hline & 543.74 & 2.18 & $3.38 \times 10^{38}$ & 485.5 & 0.962 \\
\hline \multirow{4}{*}{ EBCF-PMDA } & - & - & - & - & - \\
\hline & 43.15 & 0.24 & 43.8 & -218.4 & 0.978 \\
\hline & 97.11 & 1.53 & $1.41 \times 10^{6}$ & -133.2 & 0.982 \\
\hline & 171.94 & 1.05 & $1.30 \times 10^{10}$ & -58.7 & 0.981 \\
\hline \multirow{3}{*}{ EBCF-PA } & - & & - & - & - \\
\hline & 73.5 & 1.2 & $1.17 \times 10^{4}$ & -172.8 & 0.979 \\
\hline & 90.37 & 0.70 & $1.28 \times 10^{4}$ & -173.6 & 0.978 \\
\hline \multirow{2}{*}{ EBCF-THPA } & - & - & - & - & - \\
\hline & 136.18 & 1.40 & $9.93 \times 10^{6}$ & -98.3 & 0.973 \\
\hline \multirow{3}{*}{ EBCF-TBPA } & 48.14 & 0.39 & $1.95 \times 10^{2}$ & -205.8 & 0.962 \\
\hline & 126.95 & 1.11 & $1.27 \times 10^{5}$ & -62.9 & 0.972 \\
\hline & 164.62 & 2.59 & $1.65 \times 10^{5}$ & -50.9 & 0.992 \\
\hline \multirow{2}{*}{ EBCF-TCPA } & 110.91 & 2.63 & $5.28 \times 10^{5}$ & -62.95 & 0.985 \\
\hline & 102.81 & 2.05 & $3.63 \times 10^{9}$ & -109 & 0.972 \\
\hline
\end{tabular}

and entropy change $\left(\Delta S^{*}\right)$ are determined according to the Anderson-Freeman method [16]:

$$
\begin{aligned}
\Delta \ln \left(\frac{d W}{d t}\right) & =n \Delta \ln W-\left(\frac{E_{a}}{R}\right) \Delta\left(\frac{1}{T}\right) \\
A & =\left(\frac{E_{a} \beta}{R T^{2}}\right) e^{E / R T} \\
\Delta S^{*} & =R \ln \left(\frac{A h}{k T}\right),
\end{aligned}
$$

where $d W / d t$ is the weight loss with time, $W$ is the active weight of the substance, $\beta$ is the heating rate, $R$ is the gas constant, $h$ is the Planck's constant, $T$ is the temperature, and $k$ is the Boltzmann constant. The least square kinetic parameters $n, E_{a}$, and $A$ are reported in (Table 3 ) along with regression coefficients $\left(R^{2}\right)$. The entropy change $\left(\Delta S^{*}\right)$ was determined at corresponding $T_{\max }$ and also included in Table 3, from which it is clear that both cured and uncured resins followed either fractional or integral order decomposition kinetics. Ether and ester linkages are thermally weak points in the polymer chain, and hence, selective degradation occurs from those points on heating. The degradation may result in the formation of free radicals, which may further undergo recombination and degrade at high temperatures. The degradation process is a complex process, which involves a variety of reactions such as crosslinking, branching, recombination, and rearrangement. EBCF decomposed completely into low molecular mass substances, while EBCF-MA (37\%),
EBCF-PMDA (34\%), EBCF-PA (26\%), EBCF-THPA (21\%), EBCF-TBPA (30\%), and EBCF-TCPA (53\%) showed a considerable amount of residue at $700^{\circ} \mathrm{C}$ confirming the formation of highly thermally stable crosslinked product, which may further degrade at elevated temperatures. Large and negative magnitudes of $\Delta S^{*}$ indicated that transition state is more in orderly state than individual resin molecules and vice versa $[13,17-22]$. Thus, both nature and structure of the hardeners affected the thermal behavior of the cured resins.

\section{Conclusions}

Anhydrides cured EBCF is found insoluble in common solvents. IR spectral data supported curing of EBCF. DSC endo/exothermic transition(s) supplemented chemical or physical change when cured and uncured resins were heated under nitrogen atmosphere. Cured and uncured EBCF followed complex and multistep degradation kinetics. Thermal stability order of the cured resins is EBCF-THPA $>$ EBCF-MA $>$ EBCF-PMDA $=$ EBCF-TBPA $>$ EBCF-PA $>$ EBCF. The use of MA and THPA, EBCF-MA (37\%), EBCF-PMDA (34\%), EBCF-PA (26\%), EBCF-THPA (21\%), EBCF-TBPA (30\%), and EBCF-TCPA (53\%) showed a considerable amount of residue at $700^{\circ} \mathrm{C}$ confirming the formation of highly thermally stable crosslinked product. Curing behavior is also found dependent on both nature and structure of EBCF and hardeners used. MA and THPA hardeners proved to be the best hardeners for EBCF.

\section{Acknowledgments}

The authors are thankful to Director of SICART, V. V. Nagar (for TG analysis), Department of Science \& Technology, New Delhi and University Grants Commission, New Delhi, for instrumentation grants (DST-FIST and UGC-SAP). Jignesh P. Patel is also thankful to UGC-New Delhi Meritorious Fellowship (BSRF) for carrying out research work.

\section{References}

[1] S. A. Shokralla and N. S. Al-Muaikel, "Thermal properties of epoxy (DGEBA)/phenolic resins (novolac) blends," The Arabian Journal For Science and Engineering, vol. 35, no. 1, pp. 7-14, 2010.

[2] P. Bajpai and M. Bajpai, "Development of a high performance hybrid epoxy silicone resin for coatings," Pigment and Resin Technology, vol. 39, no. 2, pp. 96-100, 2010.

[3] T. Zhiqiang, Y. Shiyong, G. Ziyi, C. Jiansheng, and F. Lin, "Synthesis and properties of novel fluorinated epoxy resins based on 1,1-bis(4-glycidylesterphenyl)-1-(3'-trifluoromethylphenyl)2,2,2- trifluoroethane," European Polymer Journal, vol. 43, no. 2, pp. 550-560, 2007.

[4] E. M. Petrie, Epoxy Adhesive Formulations, McGraw-Hill, New York, NY, USA, 2006.

[5] H. Lee and K. Neville, Handbook of Epoxy Resin, McGraw-Hill, Rosehill, Calif, USA, 1972.

[6] X. Huang and P. Bhaskar, "Experimental characterization of a curing thermoset epoxy-anhydride system-Isothermal and nonisothermal cure kinetics," Journal of Applied Polymer Science, vol. 127, no. 3, pp. 1959-1966, 2013. 
[7] P. Musto, E. Martuscelli, G. Ragosta, and L. Mascia, "Cure kinetics and ultimate properties of a tetrafunctional epoxy resin toughened by a perfluoro-ether oligomer," Polymer, vol. 42, no. 12, pp. 5189-5198, 2001.

[8] M. Xie, Z. Wang, and Y. Zhao, "Synthesis and properties of a novel, liquid, trifunctional, cycloaliphatic epoxide," Journal of Polymer Science A, vol. 39, no. 16, pp. 2799-2804, 2001.

[9] L.-L. Lin, T.-H. Ho, and C.-S. Wang, "Synthesis of novel trifunctional epoxy resins and their modification with polydimethylsiloxane for electronic application," Polymer, vol. 38, no. 8, pp. 1997-2003, 1997.

[10] C. S. Wang and M. C. Li, "Synthesis and modification of a naphthalene-containing trifunctional epoxy resin for electronic applications," Journal of Applied Polymer Science, vol. 70, no. 10, pp. 1907-1921, 1998.

[11] P. Musto, E. Martuscelli, G. Ragosta, and L. Mascia, "Cure kinetics and ultimate properties of a tetrafunctional epoxy resin toughened by a perfluoro-ether oligomer," Polymer, vol. 42, no. 12, pp. 5189-5198, 2001.

[12] A. I. Vogel, A. R. Tatchell, B. S. Funis, A. J. Hannaford, and P. W. G. Smith, Vogel's Textbook of Practical Organic Chemistry, Addison Wesley Longman, Harlow, UK, 5th edition, 1998.

[13] J. P. Patel, P. P. Adroja, and P. H. Parsania, "Synthesis and physico-chemical study of multifunctional cardo epoxy resin and its jute fiber reinforced silica filled and unfilled composites," Journal of Polymer Materials, vol. 30, no. 1, pp. 53-64, 2013.

[14] N. Grassie, M. I. Guy, and N. H. Tennent, "Degradation of epoxy polymers: part 4-Thermal degradation of bisphenol-A diglycidyl ether cured with ethylene diamine," Polymer Degradation and Stability, vol. 14, no. 2, pp. 125-137, 1986.

[15] S. V. Levchik, G. Camino, M. P. Luda et al., "Mechanistic study of thermal behavior and combustion performance of epoxy resins: i homopolymerized TGDDM," Polymers for Advanced Technologies, vol. 6, no. 2, pp. 53-62, 1995.

[16] D. A. Anderson and E. S. Freeman, "The kinetics of the thermal degradation of polystyrene and polyethylene," Journal of Polymer Science, vol. 54, no. 159, pp. 253-260, 1961.

[17] V. M. Kagathara and P. H. Parsania, "Thermal analysis of cured chloro epoxy resins and epoxy-acrylate-styrene copolymers," Polymer Testing, vol. 21, no. 6, pp. 659-663, 2002.

[18] P. P. Adroja, S. B. Koradiya, J. P. Patel, and P. H. Parsania, "Preparation, mechanical and electrical properties of glass and jute-epoxy/epoxy polyurethane composites," Polymer, vol. 50, no. 9, pp. 937-940, 2011.

[19] P. K. Mer and P. H. Parsania, "Synthesis and thermal study of cured epoxy-acrylate-maleate, unsaturated polyester and their interpenetrating networks of varying compositions," PolymerPlastics Technology and Engineering, vol. 50, no. 3, pp. 282-287, 2011.

[20] S. Dutta, N. Karak, and S. Baruah, "Jute-fiber-reinforced polyurethane green composites based on Mesua Ferrea L. Seed oil," Journal of Applied Polymer Science, vol. 115, no. 2, pp. 843850,2010

[21] D. Ray, B. K. Sarkar, S. Das, and A. K. Rana, "Dynamic mechanical and thermal analysis of vinylester-resin-matrix composites reinforced with untreated and alkali-treated jute fibers," Composites Science and Technology, vol. 62, no. 7-8, pp. 911-217, 2002.

[22] J. P. Patel and P. H. Parsania, "Synthesis, spectral and thermal analysis of unsaturated copoly(ester-amide) of cardo epoxy resin," Journal of Polymer Materials, vol. 29, no. 4, pp. 451-457, 2012. 

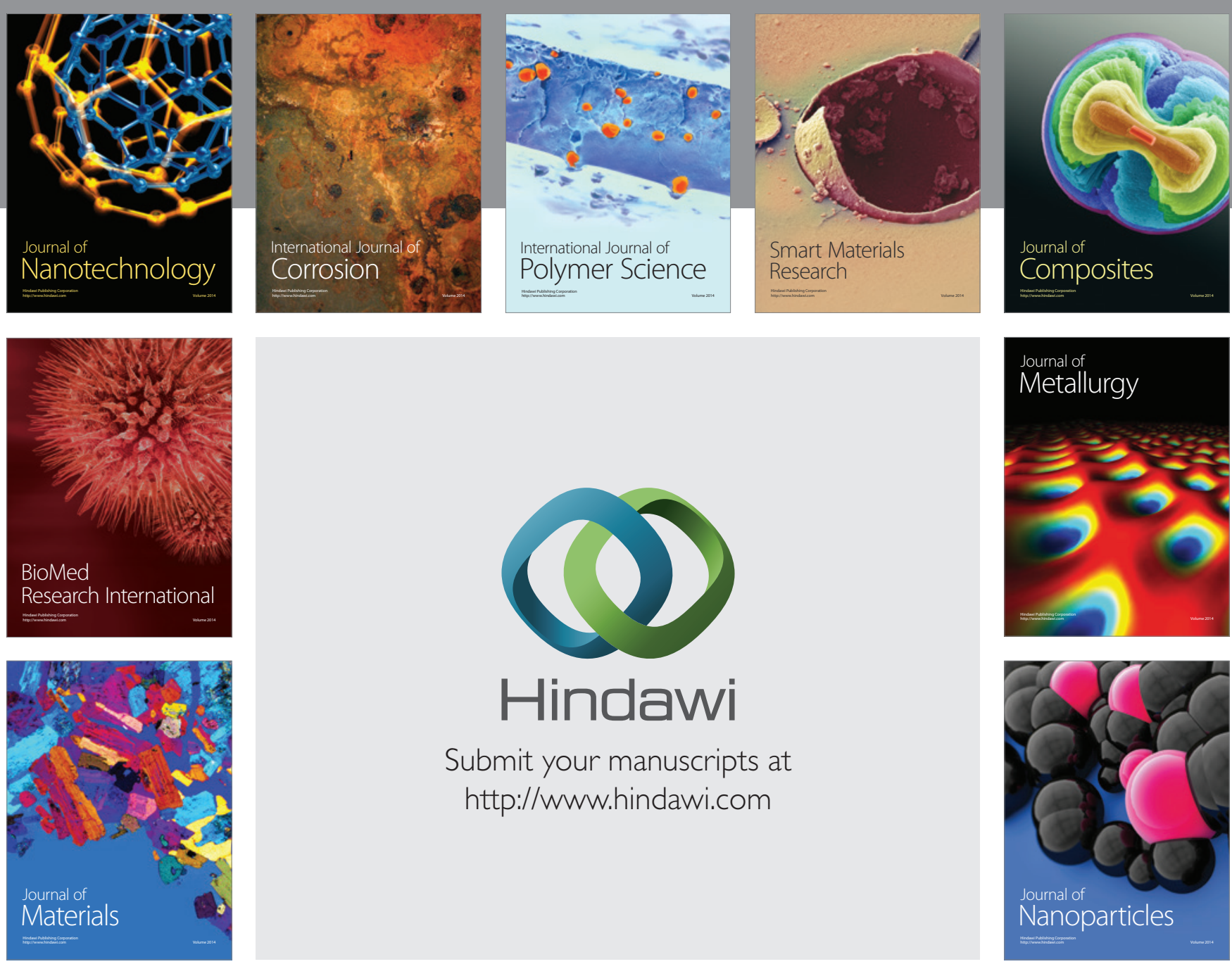

Submit your manuscripts at http://www.hindawi.com
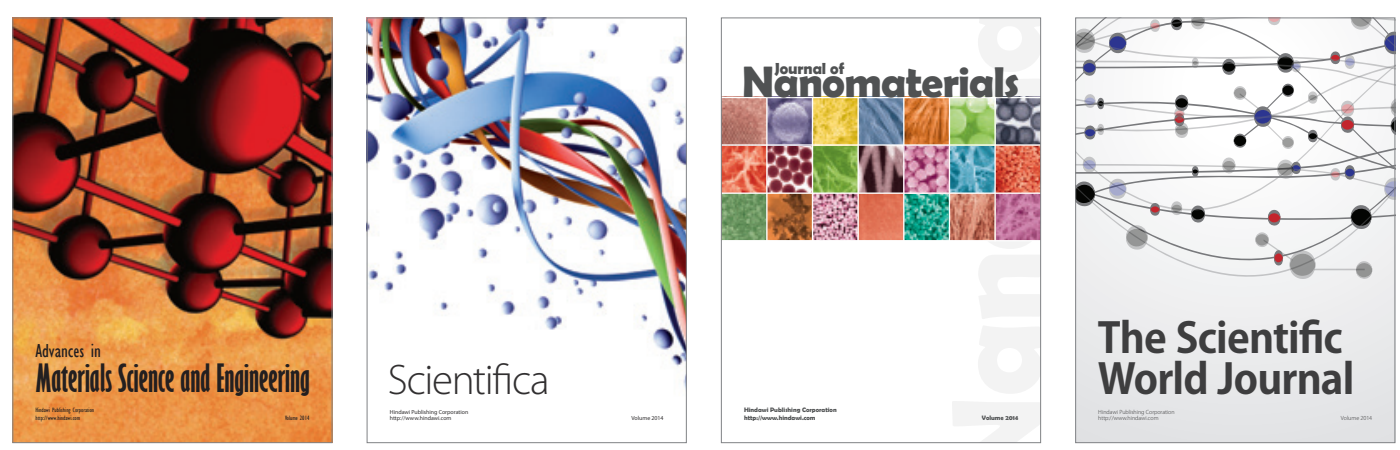

\section{The Scientific World Journal}
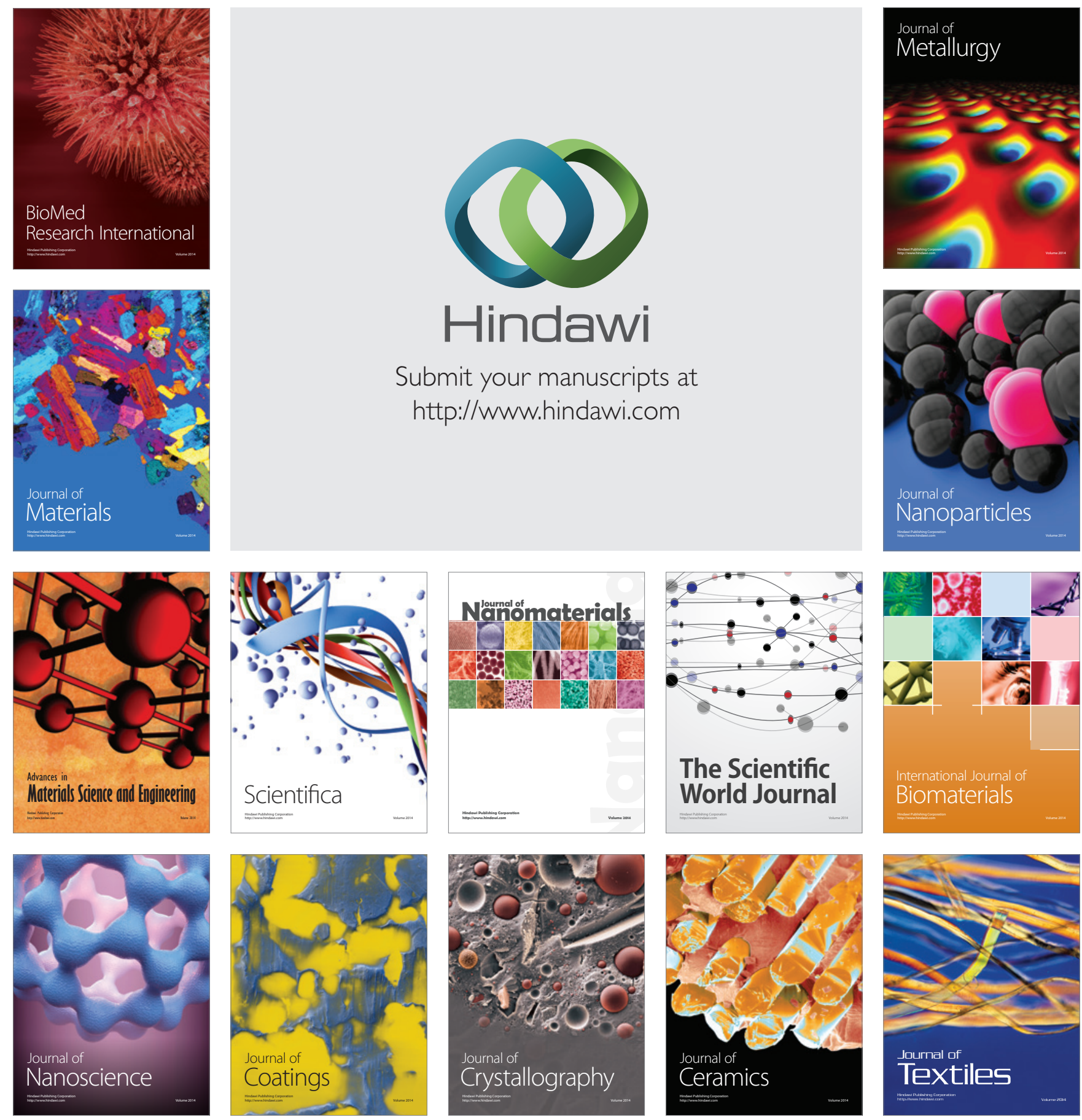